\title{
Lung clearance index: should we really go back to nitrogen washout?
}

\author{
To the Editor:
}

A recent editorial in the European Respiratory Journal [1] recognises that the fundamental scientific data on lung clearance index $(\mathrm{LCI})$ obtained by sulfur hexafluoride $\left(\mathrm{SF}_{6}\right)$ multiple-breath washout $(\mathrm{MBW})$ have paved the way for clinical use of LCI. Although the editorial stresses the need for standardisation, it also appears to suggest that $\mathrm{SF}_{6}$ can be replaced by nitrogen $\left(\mathrm{N}_{2}\right)$ as the washout gas.

We (Innovision ApS, Odense, Denmark) are the manufacturer of the AMIS 2000 medical mass spectrometer system that, using user-specific software and hardware, was adapted to perform MBW. The AMIS 2000-based devices are now considered the "gold standard" device for SF $_{6}$ LCI measurements in cystic fibrosis patients by opinion leaders in the field [2]. This device has been used in the vast majority of studies demonstrating the clinical value of $\mathrm{SF}_{6} \mathrm{LCI}$ in cystic fibrosis patients, with one recent notable exception: the demonstration of the change in LCI caused by Ivacaftor in cystic fibrosis patients with normal forced expiratory volume in $1 \mathrm{~s}$, where a prototype version of our other system, Innocor, adapted for open-circuit $\mathrm{SF}_{6} \mathrm{LCI}$, was used [3].

The AMIS 2000 adapted MBW system is too complex and too expensive for routine clinical use, and the LCI version and the required $\mathrm{SF}_{6}$ gas mixture have no regulatory approval (CE mark or US Food and Drug Administration approval). To facilitate the clinical availability of $\mathrm{SF}_{6}$-based $\mathrm{MBW}$, we have introduced the Innocor system, which, together with the gases used, is approved for clinical use and provides a much less complex and cheaper alternative to the mass spectrometer system.

In the light of the strong emphasis on standardisation in the editorial, we find the suggestion to replace $\mathrm{SF}_{6}$ with $\mathrm{N}_{2}$ surprising, as this is a major change both from a technological and a physiological standpoint for the following reasons. 1) As $\mathrm{N}_{2}$ cannot be measured by clinically available technologies, it is necessary to rely on indirect measurements, i.e. assuming that whatever is not recorded as oxygen $\left(\mathrm{O}_{2}\right)$ or carbon dioxide $\left(\mathrm{CO}_{2}\right)$ must be $\mathrm{N}_{2}$. At the LCI point, where the $\mathrm{N}_{2}$ concentration is only $\sim 2 \%$, the ability to accurately identify the $\mathrm{N}_{2}$ concentration is significantly below that recommended by the expert consensus statement to which the editorial refers [2]. 2) Washout with $100 \% \mathrm{O}_{2}$ is not equivalent to that performed with room air. During $\mathrm{N}_{2}$ washout using $100 \% \mathrm{O}_{2}$, gas viscosity changes by $\geqslant 10 \%$, which causes a significant dynamic change in the gas analyser delay time during the test and affects flow resistance in the upper airways. $\mathrm{O}_{2}$ flow across the alveolar membrane in poorly ventilated regions with end-capillary $\mathrm{O}_{2}$ saturations $<98 \%$ will also be affected when breathing $100 \% \mathrm{O}_{2}$. As this effect is smaller in well ventilated regions, distribution of ventilation will change. 3) As $\mathrm{N}_{2}$ is not insoluble in blood and tissue, the washout curve is affected by a simultaneous washout of $\mathrm{N}_{2}$ from blood and tissue (back diffusion).

Does all of this matter? Mathematically, the use of indirect measurement of $\mathrm{N}_{2}$ amplifies the relative measurement error in the sum of $\mathrm{CO}_{2}$ and $\mathrm{O}_{2}$ concentrations at the LCI point by a factor of 49 . Assuming no measurement error in $\mathrm{CO}_{2}$ :

$$
\text { Indirect } \mathrm{N}_{2} \text { at } 2 \%=100 \%-98 \% \pm \mathrm{O}_{2} \text { measurement error at } 98 \%
$$

At a relative error in $\mathrm{O}_{2}$ measurement of $0.2 \%$ :

$$
\text { Indirect } \mathrm{N}_{2}=2 \pm 0.196 \%
$$

This means that if there is a relative measurement error in the sum of $\mathrm{O}_{2}$ and $\mathrm{CO}_{2}$ concentrations of, say, $\pm 0.2 \%$ (as seen with the best $\mathrm{O}_{2}$ analysers), the relative error in the $\mathrm{N}_{2}$ concentration at the end of the washout will be $\pm 10 \%$, far in excess of that recently recommended [2].

As recognised by the consensus statement [2], the physiological impact of the use of $100 \% \mathrm{O}_{2}$ is unclear: "Thresholds at which factors such as age, sleep state and sedation interact with $100 \% \mathrm{O}_{2}$ to affect breathing pattern remain unclear".

With a reference to a study published in 1953, the consensus statement [2] states that only limited data are available on $\mathrm{N}_{2}$ back diffusion. However, a much more recent study [4] has shown a very significant $\mathrm{N}_{2}$ back diffusion from blood and tissue within the time frame of a normal washout test. The data from this study imply that almost $25 \%$ of the $\mathrm{N}_{2}$ in the lungs at the LCI point stems from back diffusion of $\mathrm{N}_{2}$. 
A recent study [5] has compared $\mathrm{N}_{2}$ LCI with $\mathrm{SF}_{6}$ LCI obtained with the gold standard method. Significant differences were found, and the authors concluded that independent normative values are required and that interventional studies are needed to clarify the role of $\mathrm{N}_{2} \mathrm{LCI}$ as an outcome measure in clinical trials in cystic fibrosis patients. The limits of agreement between $\mathrm{N}_{2}$ and $\mathrm{SF}_{6}$ LCI in cystic fibrosis patients were $>7$ LCI units, far in excess of the treatment related change reported in the Ivacaftor study of 2.1 units [3].

Finally, both the editorial [1] and the consensus statement [2] reported that the $\mathrm{SF}_{6}$ mixture required to perform LCI testing is often not universally available and not approved. This is a misunderstanding. The mixture used with the Innocor system is an off-the-shelf, 150-mL gas tank in the European Union, the USA, Canada and in all other European countries where Innocor is used.

If the reference for clinical use of the LCI test is the scientific data obtained with the gold standard mass spectrometer device over many years of research, the suggestion to switch to $\mathrm{N}_{2}$ LCI is premature and scientifically unfounded. Notwithstanding the well recognised problems of indirect $\mathrm{N}_{2}$ measurement and the physiological effects of pure $\mathrm{O}_{2}$, recent research has also highlighted that $\mathrm{N}_{2}$ back diffusion may be much more important than previously thought.

\section{0} @ERSpublications

Multiple-breath washout: nitrogen or sulfur hexafluoride? http://ow.ly/pUW49

Jørgen G. Nielsen

Innovision ApS, Odense, Denmark.

Correspondence: J.G. Nielsen, Innovision ApS, Lindvedvej 75, 5260 Odense S, Denmark. E-mail: jgn@innovision.dk

Received: April 192013 | Accepted after revision: July 312013

Conflict of interest: Disclosures can be found alongside the online version of this article at www.erj.ersjournals.com

\section{References}

1 Schulzke SM, Frey U. Consensus statement on inert gas washout measurement: at the threshold of clinical use. Eur Respir J 2013; 42: 500-502.

2 Robinson PD, Latzin P, Verbanck S, et al. Consensus statement for inert gas washout measurement using multipleand single- breath tests. Eur Respir J 2013; 41: 507-522.

3 Ratjen FA, Sheridan H, Lee P-S, et al. Lung clearance index as an endpoint in a multicenter randomized control trial of Ivacaftor in subjects with cystic fibrosis who have mild lung disease. Am J Respir Crit Care Med 2012; 185: A2819.

4 Pendergast DR, Senf C, Lundgren CE. Is the rate of whole-body nitrogen elimination influenced by exercise? Undersea Hyperb Med 2012; 39: 595-604.

5 Jensen R, Stanojevic S, Gibney K, et al. Multiple breath nitrogen washout: a feasible alternative to mass spectrometry. PLoS One 2013; 8: e56868.

Eur Respir J 2014; 43: 655-656 | DOI: 10.1183/09031936.00069913 | Copyright @eERS 2014

\section{From the authors:}

We thank J.G. Nielson for his comments about our editorial related to the consensus statement for inert gas washout measurement using multiple- and single-breath tests recently published in the European Respiratory Journal $[1,2]$. Given that we are unable to identify relevant new information concerning the topic at hand, we prefer not to add any further comments and kindly refer to the previously mentioned, very elaborate, consensus statement [2].

\section{O} @ERSpublications

Consensus statement for inert gas washout measurement http://ow.ly/rm6nI

Sven M. Schulzke and Urs Frey

University Children's Hospital Basel (UKBB), Basel, Switzerland.

Correspondence: S.M. Schulzke, Dept of Neonatology, University Children's Hospital Basel (UKBB), Spitalstrasse 33, CH-4056 Basel, Switzerland. E-mail: sven.schulzke@unibas.ch

Received: Nov 202013 | Accepted: Nov 212013

Conflict of interest: None declared. 